\title{
ANALISIS PERUBAHAN FUNGSI RUANG PADA CAGAR BUDAYA KLINIK BETHESDA PETERONGAN
}

\author{
Kurniawan Bayuaji, Satrio Nugroho* \\ *)Corresponding author email : $\underline{\text { satrionugroho@arsitektur.undip.ac.id }}$ \\ Departemen Arsitektur, Fakultas Teknik, Universitas Diponegoro
}

Article info

MODUL vol 18 no 2, issues period 2018

Doi $\quad: 10.14710 / \mathrm{mdl} .18 .2 .2018 .70-74$

Received : 24 Oct 2018

Revised : 26 Oct 2018

Accepted : 29 Oct 2018

\begin{abstract}
Klinik Bethesda Peterongan merupakan salah satu bangunan Cagar Budaya yang dilestarikan oleh Pemerintah Kota Semarang. Bangunan ini awalnya merupakan rumah tinggal milik keluarga Tan Siang Swie. Namun, seiring berjalannya waktu bangunann ini sekarang difungsikan sebagai klinik yang kepengurusannya menjadi satu dengan GKI Peterongan. Tentunya, sebagai cagar budaya bangunan ini memiliki nilai penting yang patut untuk dilestarikan agar bisa menjadi objek studi di masa yang akan datang. Namun, penggunaan bangunan lama dengan fungsi baru terkadang memaksa pemilik atau pengelola bangunan untuk memenuhi kebutuhan dari bangunan ini, dan terkadang hal tersebut bisa saja bersifat merusak. Maka dari itu, diperlukan sebuah tinjauan mengenai bagaimana tindakan pelestarian yang sudah dilakukan pada bangunan ini, dan bagaimana rekomendasi tindakan yang seharusnya dilakukan pada bangunan ini di masa yang akan datang
\end{abstract}

Keywords: Cagar Budaya; Pelestarian; Klinik

\section{LATAR BELAKANG}

Klinik Bethesda Peterongan merupakan salah satu bangunan Cagar Budaya yang dilestarikan oleh Pemerintah Kota Semarang. Bangunan ini awalnya merupakan rumah tinggal milik keluarga Tan Siang Swie.

Kurniawan Bayuaji, Satrio Nugroho

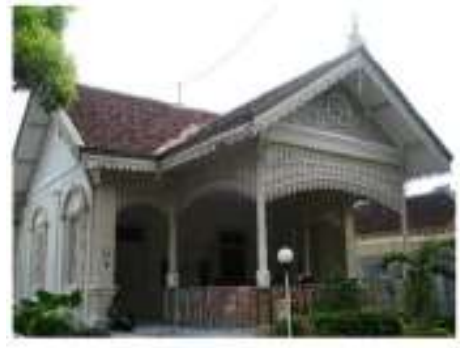

Gambar 1. Eksterior Klinik Bethesda

Tentunya, sebagai cagar budaya bangunan ini memiliki nilai penting yang patut untuk dilestarikan agar bisa menjadi objek studi di masa yang akan datang. Otentisitas dari bangunan ini harus senantiasa dijaga agar tetap terawat dan tidak rusak, baik kerusakana itu yang berasal dari alam ataupun yang dikarenakan oleh tindakan manusia. Adapun tindakan pelestarian tersebut harus didasari oleh prinsip dan argumen yang tepat sehingga tidak terjadi kekeliruan.

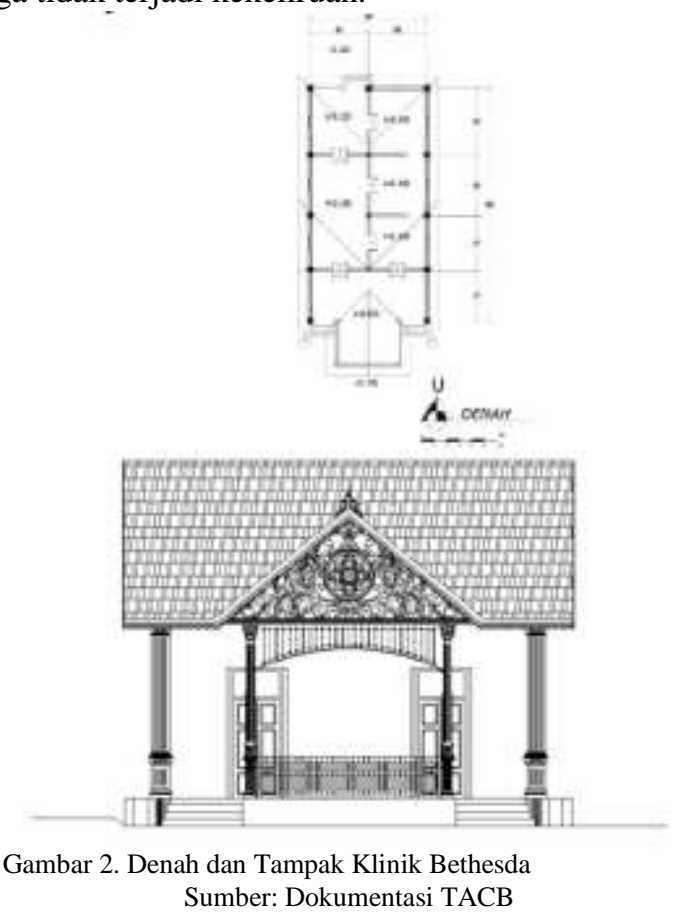


Namun, penggunaan bangunan lama dengan fungsi baru terkadang memaksa pemilik atau pengelola bangunan untuk memenuhi kebutuhan dari bangunan ini, dan terkadang hal tersebut bisa saja bersifat merusak. Beberapa contoh misalnya, dengan fungsi baru sebagai klinik, maka harus ada susunan ruangan yang diubah sehingga harus ada penambahan sekat di dalam bangunan. Terkadang, penambahan sekat tersebut kurang baik sehingga merusak lantai atau dinding dari bangunan ini. Ada juga beberapa hal yang seringkali merusak misalnya dengan adanya pipa AC yang menembus dinding, ataupun hal-hal lain yang bersifat mengurangi nilai otentisitas dari objek arsitektur cagar budaya. Maka dari itu, diperlukan sebuah tinjauan mengenai bagaimana tindakan pelestarian yang sudah dilakukan pada bangunan ini, dan bagaimana rekomendasi tindakan yang seharusnya dilakukan pada bangunan ini di masa yang akan datang.

\section{RUMUSAN MASALAH}

Rumusan masalah yang dibahas dalam penelitian ini adalah:

- Bagaimana perubahan fungsi yang terjadi pada Klinik Bethesda?

- Apakah bangunan cagar budaya Rumah Tinggal Tan Siang Swie dapat mewadahi fungsi barunya sebagai klinik?

\section{TUJUAN}

Penelitian ini bertujuan untuk menganalisis perubahan fungsi ruang pada Klinik Bethesda Peterongan

\section{KAJIAN PUSTAKA \\ Definisi Cagar Budaya}

Menurut UU No. 11 tahun 2010, pasal 1, ayat (2) s.d. (6) Benda Cagar Budaya adalah benda alam dan/atau benda buatan manusia, baik bergerak maupun tidak bergerak, berupa kesatuan atau kelompok, atau bagian-bagiannya, atau sisa-sisanya yang memiliki hubungan erat dengan kebudayaan dan sejarah perkembangan manusia. Bangunan Cagar Budaya adalah susunan binaan yang terbuat dari benda alam atau benda buatan manusia untuk memenuhi kebutuhan ruang berdinding dan/atau tidak berdinding, dan beratap. Struktur Cagar Budaya adalah susunan binaan yang terbuat dari benda alam dan/atau benda buatan manusia untuk memenuhi kebutuhan ruang kegiatan yang menyatu dengan alam, sarana, dan prasarana untuk menampung kebutuhan manusia. Situs Cagar Budaya adalah lokasi yang berada di darat dan/atau di air yang mengandung Benda Cagar Budaya, Bangunan Cagar Budaya, dan/atau Struktur Cagar Budaya sebagai hasil kegiatan manusia atau bukti kejadian pada masa lalu.
Kawasan Cagar Budaya adalah satuan ruang geografis yang memiliki dua Situs Cagar Budaya atau lebih yang letaknya berdekatan dan/atau memperlihatkan ciri tata ruang yang khas. Menurut UNESCO basic texts of the 1972 World Heritage Convention, Article 1 For the purpose of this Convention, the following shall be considered as "cultural heritage": monuments: architectural works, works of monumental sculpture and painting, elements or structures of an archaeological nature, inscriptions, cave dwellings and combinations of features, which are of outstanding universal value from the point of view of history, art or science; groups of buildings: groups of separate or connected buildings which, because of their architecture, their homogeneity or their place in the landscape, are of outstanding universal value from the point of view of history, art or science; sites: works of man or the combined works of nature and man, and areas including archaeological sites which are of outstanding universal value from the historical, aesthetic, ethnological or anthropological point of view.

\section{Prinsip Tindakan Pelestarian \\ Menurut Ferdinand von Quast (1807-1877),} seorang arsitek dan sejarawan yang menjadi Konservator Kunst-denkmaler dan murid dari Schinkel sejak 1827. Sebagai konservator, ia bertanggung jawab meng-hentikan perusakan dan kehancuran monumen ber-sejarah serta memperjelas konsep monumen tanpa pengecualian, seperti ungkapannya: "apa pun jenis konstruksinya, asalkan memiliki signifikansi artistik atau monumental, baik berwujud gambar, lukisan, karya seni, atau yang lainnya; dan tidak hanya benda yang dimiliki kerajaan atau kota, atau dimiliki korporasi, atau jika tanggung jawab perawatannya diserahkan kepada perorangan untuk dipelihara dalam status quo"

Prinsip dasar restorasi von Quast yang disebut "purification" adalah penolakan terhadap pendekatan "artistik" atau "arkeologikal". Menurutnya pendekatan artistik dan arkeologikal bersifat merusak. Ia berupaya merestorasi bangunan dengan menghormati seluruh bagian struktur dan monumen yang berasal dari jaman berbeda karena memiliki nilai seni atau kesejarahan. Ketika material yang lebih baru menutupi material lama, maka amat diperlukan penilaian kritis untuk memutuskan dihilangkannya material yang lebih baru demi memperbaiki yang lama.

Penilaian tersebut terdapat dalam pandangannya:

"perbaikan harus dibatasi secara minimum, hanya yang diperlukan saja, sejauh untuk keselamatan bangunan dan keseluruhan karakteristik tampilannya yang memungkinkan. Ahli bangunan perlu harus menghormati keaslian, dan kehati-hatian dalam perbaikan" 
Menurut International Charter For The Conservation And Restoration Of Monuments And Sites pada The Venice Charter 1964, dinyatakan bahwa: "Diingat dengan sebuah pesan dari masa lalu, monumen bersejarah masyarakat tetap bertahan sampai sekarang sebagai saksi hidup dari tradisi kuno mereka. Orang menjadi semakin sadar akan kesatuan nilai-nilai kemanusiaan dan menganggap monumen kuno sebagai warisan bersama. Tanggung jawab masyarakat adalah untuk melindungi mereka agar generasi penerus bisa mengenali. Adalah tugas kita untuk menyerahkannya dalam kekayaan keaslian mereka secara keseluruhan ".

\section{Standar Sarana Klinik}

Menurut Permenkes No 9 Tahun 2014, dinyatakan bahwa:

Pasal 6

1) Bangunan Klinik harus bersifat permanen dan tidak bergabung fisik bangunannya dengan tempat tinggal perorangan.

2) Ketentuan tempat tinggal perorangan sebagaimana dimaksud pada ayat (1) tidak termasuk apartemen, rumah toko, rumah kantor, rumah susun, dan bangunan yang sejenis.

3) Bangunan Klinik harus memperhatikan fungsi, keamanan, kenyamanan dan kemudahan dalam pemberian pelayanan serta perlindungan keselamatan dan kesehatan bagi semua orang termasuk penyandang cacat, anak-anak dan orang usia lanjut

Pasal 7

1) Bangunan Klinik paling sedikit terdiri atas:

a. ruang pendaftaran/ruang tunggu;

b. ruang konsultasi;

c. ruang administrasi;

d. ruang obat dan bahan habis pakai untuk klinik yang melaksanakan pelayanan farmasi;

e. ruang tindakan;

f. ruang/pojok ASI;

g. kamar mandi/wc; dan

h. ruangan lainnya sesuai kebutuhan pelayanan.

\section{DATA}

Ketika pertama dibangun sebagai kediaman rumah Tan Siang Swie, klinik ini berupa bangunan satu lantai dengan pola ruang yang simetris. Organisasi ruangnya linear. Penempatan posisi jendela dan pintu selalu sama dan berulang pada setiap ruangan.

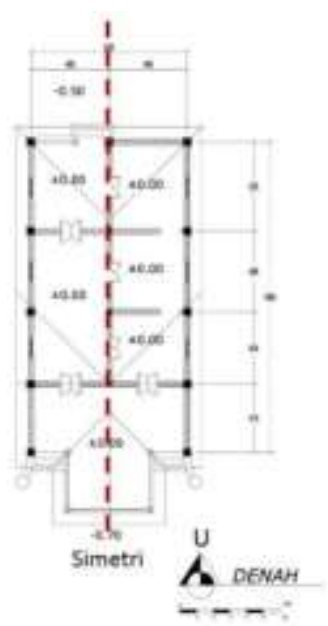

Gambar 3. Tata Ruang Asli Sumber: Dokumentasi TABG

ruang resepsionis

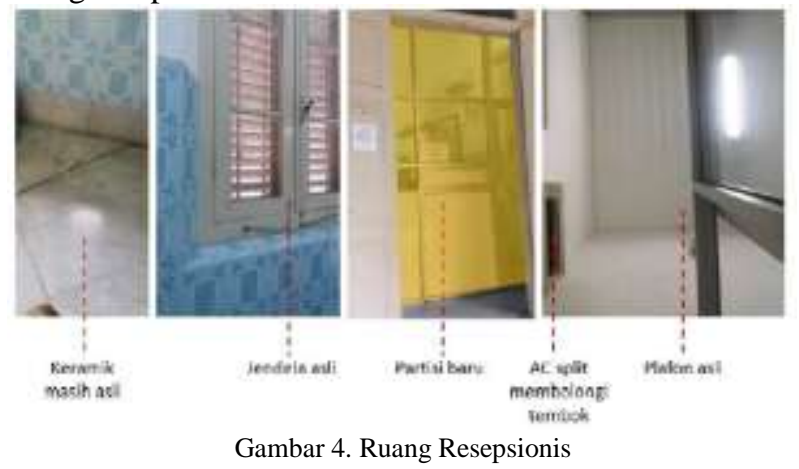

Ruang resepsionis masih banyak menggunakan elemen asli, namun demi alasan fungsional, maka pihak pengelola menambahkan partisi alumunium di ruang tersebut. Ruang resepsionis tersebut menggunakan AC split yang merusak tembok asli bangunan.

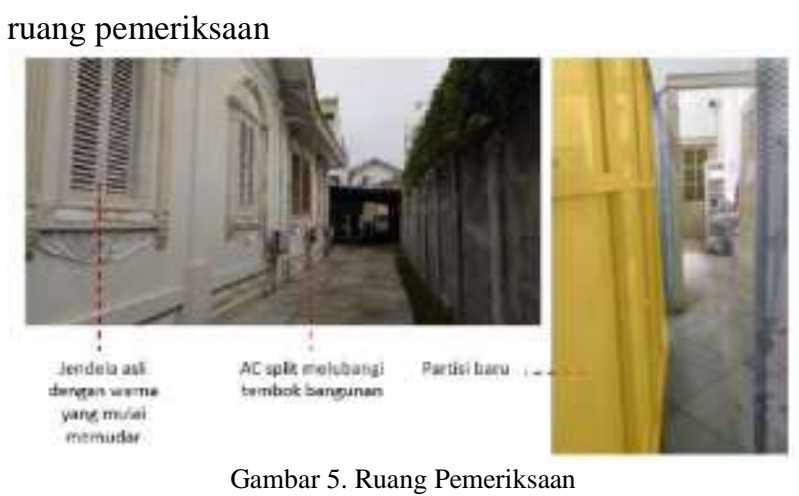

Ruang pemeriksaan sudah merubah tata ruang awal Klinik Bethesda dengan penambahan berbagai partisi baru. Selain itu, AC split yang berada di ruangan ini membutuhkan lubang sehingga merusak tembok 
ruang obat

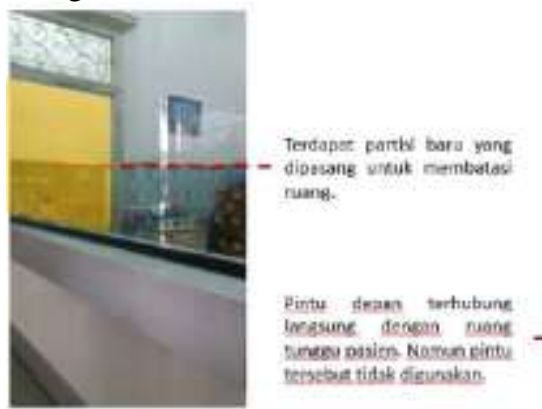

Gambar 6. Ruang Obat

Ruang obat berada di sebelah ruang resepsionis yang dihubungkan dengan pintu. Ruangan ini merupakan bagian dari ruang kerja kantor yang dipisahkan menggunakan partisi baru

ruang kerja kantor

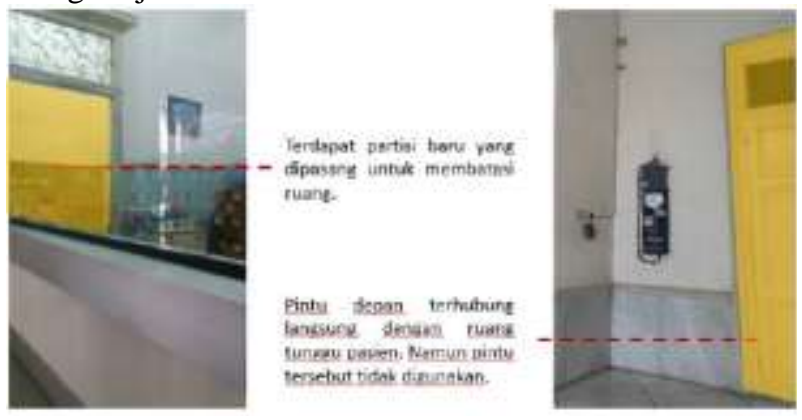

Gambar 7. Ruang Kerja Kantor

Berbagai pajangan di dalam ruang kerja kantor membuat dinding klinik menjadi berlubang akibat paku. Di dalam kantor terlihat ada partisi baru yang merupakan partisi ruang obat.

ruang tamu kantor

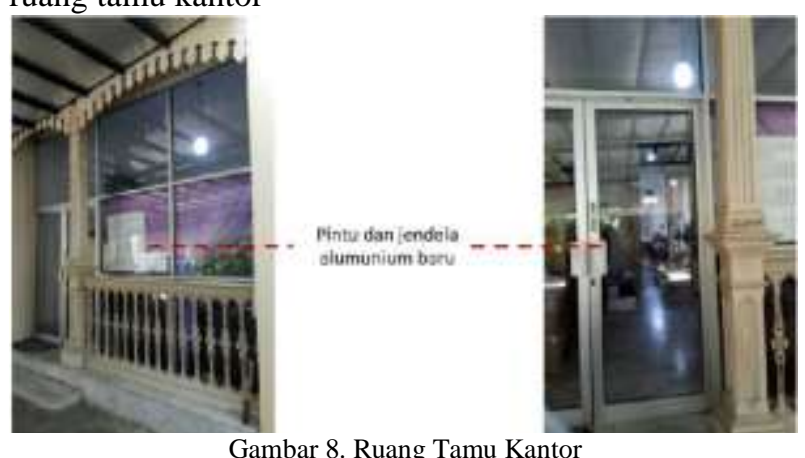

Ruang tamu kantor memiliki tambahan partisi alumunium. Pintu tersebut berada di dekat teras yang awalnya terbuka.

\section{ANALISA}

Untuk menganalisis bangunan ini, maka ada dua aspek yang dinilai pemanfataanya yaitu:

- Tata ruang

- Penggunaan Material

Adapun untuk penilaiannya menggunakan skala 1-5 dengan keterangan sebagai berikut:

- Nilai 1 berarti sangat buruk, diberikan jika aspek yang dinilai bersifat merusak bangunan

- $\quad$ Nilai 2 berarti buruk, diberikan jika aspek yang dinilai belum terpenuhi secara sepenuhnya dan melanggar prinsip pelestarian

- $\quad$ Nilai 3 berarti biasa, diberikan jika aspek yang dinilai belum tercapai secara sepenuhnya namun tidak melanggar prinsip pelestarian

- Nilai 4 berarti baik, diberikan jika aspek yang dinilai sudah tercapai secara sepenuhnya dan tidak melanggar prinsip pelestarian

- $\quad$ Nilai 5 berarti sangat baik, diberikan jika aspek yang dinilai sudah tercapai secara sepenuhnya, tidak melanggar prinsip pelestarian dan berdampak positif bagi keberlanjutan bangunan

Adapun nilai tersebut juga bisa bertambah atau berkurang sesuai dengan penilaian dari pengamatan dari lapangan

Tabel 1. Rekapitulasi Nilai

Tata Ruang

\begin{tabular}{|c|c|c|}
\hline Aspek & Kondisi & Nilai \\
\hline $\begin{array}{l}\text { Ruang } \\
\text { pendaftaran/Rua } \\
\text { ng tunggu }\end{array}$ & $\begin{array}{l}\text { Kondisi ruang tunggu di } \\
\text { portico sudah cukup baik dan } \\
\text { mampu menampung pasien } \\
\text { yang menunggu. Namun pada } \\
\text { bagian ruang resepsionis, } \\
\text { terdapat penambahan partisi. }\end{array}$ & 3 \\
\hline Ruang konsultasi & $\begin{array}{l}\text { Terdapat penambahan partisi } \\
\text { baru di bagian ruang } \\
\text { pemeriksaan }\end{array}$ & 2 \\
\hline $\begin{array}{l}\text { Ruang } \\
\text { administrasi }\end{array}$ & $\begin{array}{l}\text { Bagian ruang tunggu kantor } \\
\text { menambahkan pintu } \\
\text { alumunium baru. Pajangan di } \\
\text { dalam ruang kantor melubangi } \\
\text { dinding bangunan. Selain itu } \\
\text { penggunaan AC merusak } \\
\text { dinding bangunan asli }\end{array}$ & 1 \\
\hline $\begin{array}{l}\text { Ruang obat dan } \\
\text { bahan habis } \\
\text { pakai }\end{array}$ & $\begin{array}{l}\text { Ruang obat sepenuhnya } \\
\text { terbuat dari partisi baru, } \\
\text { bukan memanfaatkan ruang } \\
\text { yang sudah ada sebelumnya. }\end{array}$ & 2 \\
\hline Ruang tindakan & $\begin{array}{l}\text { Penggunaan AC di ruang } \\
\text { tindakan pasien merusak } \\
\text { dinding bangunan asli. }\end{array}$ & 1 \\
\hline $\begin{array}{l}\text { Ruang/pojok } \\
\text { ASI }\end{array}$ & Tidak tersedia & 2 \\
\hline $\begin{array}{l}\text { Kamar } \\
\text { mandi/WC }\end{array}$ & $\begin{array}{l}\text { WC masih menumpang pada } \\
\text { bangunan lain di GKI } \\
\text { Peterongan }\end{array}$ & 2 \\
\hline
\end{tabular}


Penggunaan Material

\begin{tabular}{|c|c|c|}
\hline Plafon & $\begin{array}{l}\text { Plafon yang digunakan masih } \\
\text { asli dan sesuai dengan kondisi } \\
\text { awalnya }\end{array}$ & 3 \\
\hline Lantai & $\begin{array}{l}\text { Lantai mengalami sedikit } \\
\text { kerusakan, namun } \\
\text { mayoritasnya masih sesuai } \\
\text { dengan kondisi awal }\end{array}$ & 2 \\
\hline Dinding & $\begin{array}{l}\text { Ada banyak dinding yang } \\
\text { berlubang akibat penggunaan } \\
\text { AC. Selain itu ada banyak } \\
\text { partisi baru yang digunakan, } \\
\text { namun partisi itu tidak } \\
\text { permanen dan bisa dibedakan } \\
\text { dengan elemen aslinya }\end{array}$ & 2 \\
\hline Struktur & $\begin{array}{l}\text { Struktur masih menggunakan } \\
\text { struktur yang asli sesuai } \\
\text { kondisi awalnya }\end{array}$ & 3 \\
\hline Jendela & $\begin{array}{l}\text { Jendela masih belum bisa } \\
\text { memenuhi kebutuhan klinik, } \\
\text { sehingga pengkondisian udara } \\
\text { dan pencahayaan tidak bisa } \\
\text { menggunakan cahaya alami } \\
\text { dan penghawaan alami } \\
\end{array}$ & 2 \\
\hline Pintu & $\begin{array}{l}\text { Tidak semua sirkulasi pintu } \\
\text { dapat digunakan bagi klinik, } \\
\text { ada beberapa pintu yang tidak } \\
\text { digunakan. Selain itu demi } \\
\text { alasan keamanan, perlu } \\
\text { dipasang pintu-pintu yang } \\
\text { baru dari alumunium, tidak } \\
\text { dapat menggunakan pintu } \\
\text { yang sudah ada. }\end{array}$ & 3 \\
\hline TOTAL & & 28 \\
\hline
\end{tabular}

\section{KESIMPULAN}

Skor yang didapat oleh klinik Bethesda adalah 28 poin dari total skor maksimal 65 poin

$28 / 65 \times 100 \%=43 \%$

Maka, dapat disimpulkan, bahwa dengan perubahan fungsi seperti saat ini, Bangunan Cagar Budaya ini hanya mampu memenuhi $43 \%$ kebutuhan di dalamnya ketika ditinjau dari sisi pelestarian bangunan.

\section{SARAN}

Penggunaan fungsi baru pada bangunan Klinik Bethesda sebaiknya mempertimbangkan prinsip pelestarian dan tidak merusak bangunan. Perlu dipertimbangkan mengenai fungsi lain apabila fungsi sebagai klinik tidak bisa terakomodir pada bangunan ini

\section{DAFTAR PUSTAKA}

Hartono, S. \& Handinoto (2006). Arsitektur Transisi Di Nusantara Dari Akhir Abad 19 Ke Awal Abad 20. DIMENSI: Journal of Architecture of and Built Environtment Vol 34 No.2, ISSN 23387858

ICOMOS (1964). International Charter For The Conservation And Restoration Of Monuments And Sites. Venice: ICOMOS.
Jokilehto, J. (2007) History of Architectural Conservation, First Edition. Routledge. ISBN 113639849X, 9781136398490

(2017) History of Architectural Conservation, Second Edition. Routledge. ISBN 131726651X, 9781317266518

UNESCO (2005). Basic texts of the 1972 World Heritage Convention. Paris: the United Nations Educational, Scientific and Cultural Organization.

Regulasi:

$\square$ Undang-Undang No 11 Tahun 2010 tentang Cagar Budaya

Peraturan Menteri Kesehatan Republik Indonesia Nomor 9 Tahun 2014 Tentang Klinik 